\title{
FREE STATION TASK WITH DRONE
}

\author{
David Zahradník
}

\section{Czech Technical University in Prague, Faculty of Civil Engineering, Department of Geomatics, Thákurova 7, Praha 6, Czech Republic; david.zahradnik@fsv.cvut.cz}

\begin{abstract}
The main purpose of drones is to take pictures, but different developers are inventing new possibilities of use. Drones are used mainly for reconnaissance. During survey they can be also used in other ways than taking pictures. A drone containing GNSS RTK and a prism can be used as an orientation point for a total station. The idea of this use is based on the need to establish a boundary of ownership in the forest. Forests with tall trees are bad for GNSS receivers, the signal will not go through the treetops and the GNSS receiver cannot pinpoint its location. When the GNSS receiver reaches above the trees, it is possible to receive the GNSS signal and determine the position of the GNSS receiver. Position projection in terrain is problematic. The first method is to project the position of the GNSS receiver along the vertical axis by some measurement equipment. The second method involves using a total station and prism. The free station method is used with a connection to orientation points on a drone. This article discusses the accuracy of the free station task with the connection to orientation points on a drone.
\end{abstract}

\section{KEYWORDS}

Free station task, Drone, Precision analysis

\section{INTRODUCTION}

Drones are an important part of surveys. Land surveying is much faster and allows analyzing larger areas with similar accuracy [1] [2]. Use of dronesgrows with various devices deployed on the drone like LIDAR, etc.

3D models of buildings and structures can be created using drones, but sometimes it is difficult to fly with drones in a limited space. A combination of total station and drone solves this problem [3] [4] [5] [6] [7] [8]. Total station measures the position of the drone and it sends this information to the drone program. This helps to fly it more precisely than drones equipped with GNSS RTK.

Other works show that drones can place construction points in the field. Drone flies to the approximate position of the construction points. Drone lands on the plane and it starts measuring the observation by RTK method. Difference between drone position and construction point is set by mechanical tools on the drone. After setting the right position of the mechanical tool, drone drills nail into the ground and construction point is stabilized. [9]

The drone is equipped with a pri sm and a GNSS receiver. GNSS receivers must allow centimeter position accuracy. Drone serves as orientation points, total station measure on them and it calculates the coordinates of its position. This method applies to locations without permanent points and without a GNSS signal. Traditionally permanent points are created by polygon method via total station. Primary permanent points are measured by GNSS receiver in an environment with good GNSS signal and secondary permanent points are measured by total station in forest. This method is time consuming and expensive. Combination of total station and drone will help accelerate this type of measurement. 


\section{METHODS}

A free station task is used for combination measuring of a total station and a drone. Drone with GNSS RTK receiver and prism serves as orientation points. Total station measures on drone and calculates its coordinates. Precision of this method must be known for its credibility.

Orientation points have a main effect on resulting precision. Precision of orientation points depends on precision of GNSS receiver, horizontal offset between prism and GNSS antenna and drone movements in specific air conditions.

Ublox F9P with ANN-BN antenna is used as a GNSS receiver. Horizontal and vertical position accuracy of the module in RTK method is $1 \mathrm{~cm}+1 \mathrm{ppm}$ given by the datasheet. Position accuracy from manufacture is confirmed by testing this module [10]. Some studies also confirmed this claim in open space without multipath [11] [12].

Horizontal offset is minimized in design solutions, and it causes the smallest errors of all three aspects.

Drone movement must be considered. The drone is constantly moving. Drone holds position via GNSS, IMU, and visual sensors. If a drone flies in the wind, the system reacts after changing position. This causes time gaps in the holding position process, so the drone moves. Drone movements in the holding position function are determined in this article.

A process of a free station task with drone depends on a total station and a drone. At least two permanent points must be created by this method to allow subsequent measurement. Two places must be found with visibility to the sky for permanent points. Total station is prepared for measurement and the drone flies above trees. GNSS receiver on drone starts to measure coordinates. Distance, horizontal and vertical angle are measured by total station to prism on the drone. When two orientation points are measured, total station calculates its coordinates.

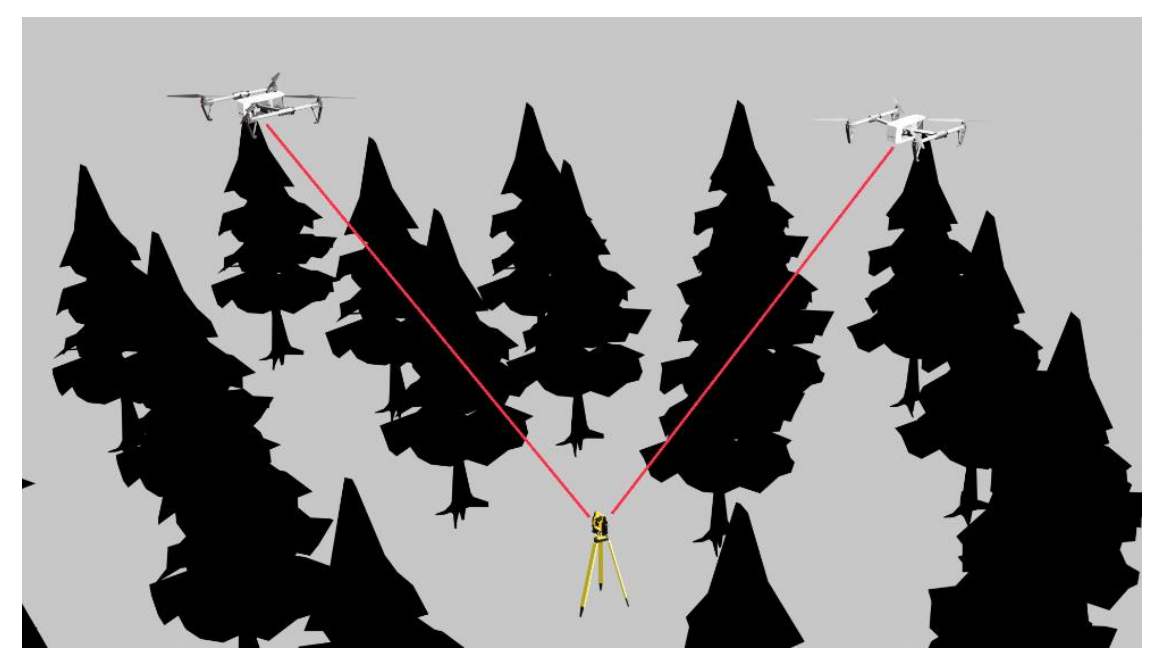

Fig. 1 - Free station task scheme

The configuration of orientation points and total station have also an effect on position accuracy.

There is limited visibility in the forest, so it is important to know limitations of free station task. The article deals with free station tasks with two orientation points. High visibility is not expected in the forest, so only two orientation points are planned.

Free station task is done by the least squares method. It is the most common calculation method used in total station software. 


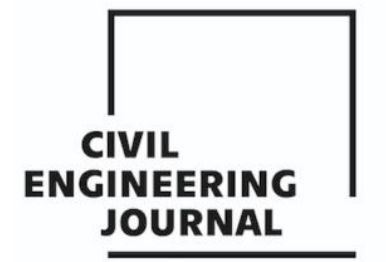

Article no. 57

THE CIVIL ENGINEERING JOURNAL 3-2021

\section{Drone construction}

DJI Mavic 2 has been selected for this experiment. Ublox F9P with ANN-BN antenna are installed on top of the drone. GNSS receiver is independent, and it does not control drone movement. GNSS receiver is connected via NTRIP client to receive data of reference stations from CZEPOS network. [13]

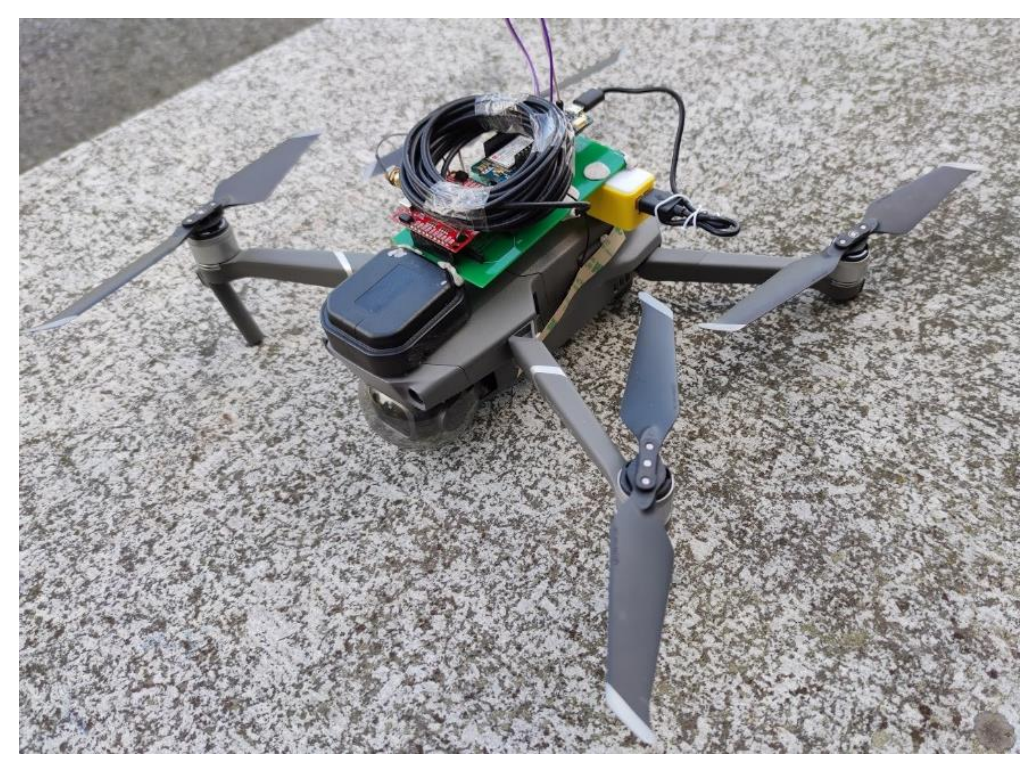

Fig. 2 - DJI Mavic 2 PRO + Ublox F9P

\section{Drone movements}

Precision of orientation points affects drone movement in different wind conditions. The test of drone movements reveals how much the wind affects drone movement.

The test was performed twice, in windy $(15 \mathrm{~m} / \mathrm{s})$ conditions and windless $(5 \mathrm{~m} / \mathrm{s})$ and the test has been verified by two methods. First method was done by installing an independent GNSS receiver and GNSS receiver measures drone positions. In the second method prism was installed on the drone, and it was measured by total station. Drone was holding position $30 \mathrm{~m}$ above ground in open space, where it was exposed to the wind.

First method is done by a GNSS receiver with RTK method, position data was recorded for 5 minutes in each wind condition and was analyzed for finding standard deviation of drone movements. Results are presented in Table1.

In the second test, the position of the drone was measured by total station with automatic targeting. Position was measured in the same conditions as the first test, in wind $(15 \mathrm{~m} / \mathrm{s})$ and windless $(5 \mathrm{~m} / \mathrm{s})$. Drone was flying $30 \mathrm{~m}$ above the ground and the distance between the total station and drone was $50 \mathrm{~m}$. Position was measured every 15 seconds for 5 minutes, 20 positions were captured. Results are in Table 2.

Data from the second method was analyzed and compared to the first method. The second method verifies the results of the first method. 


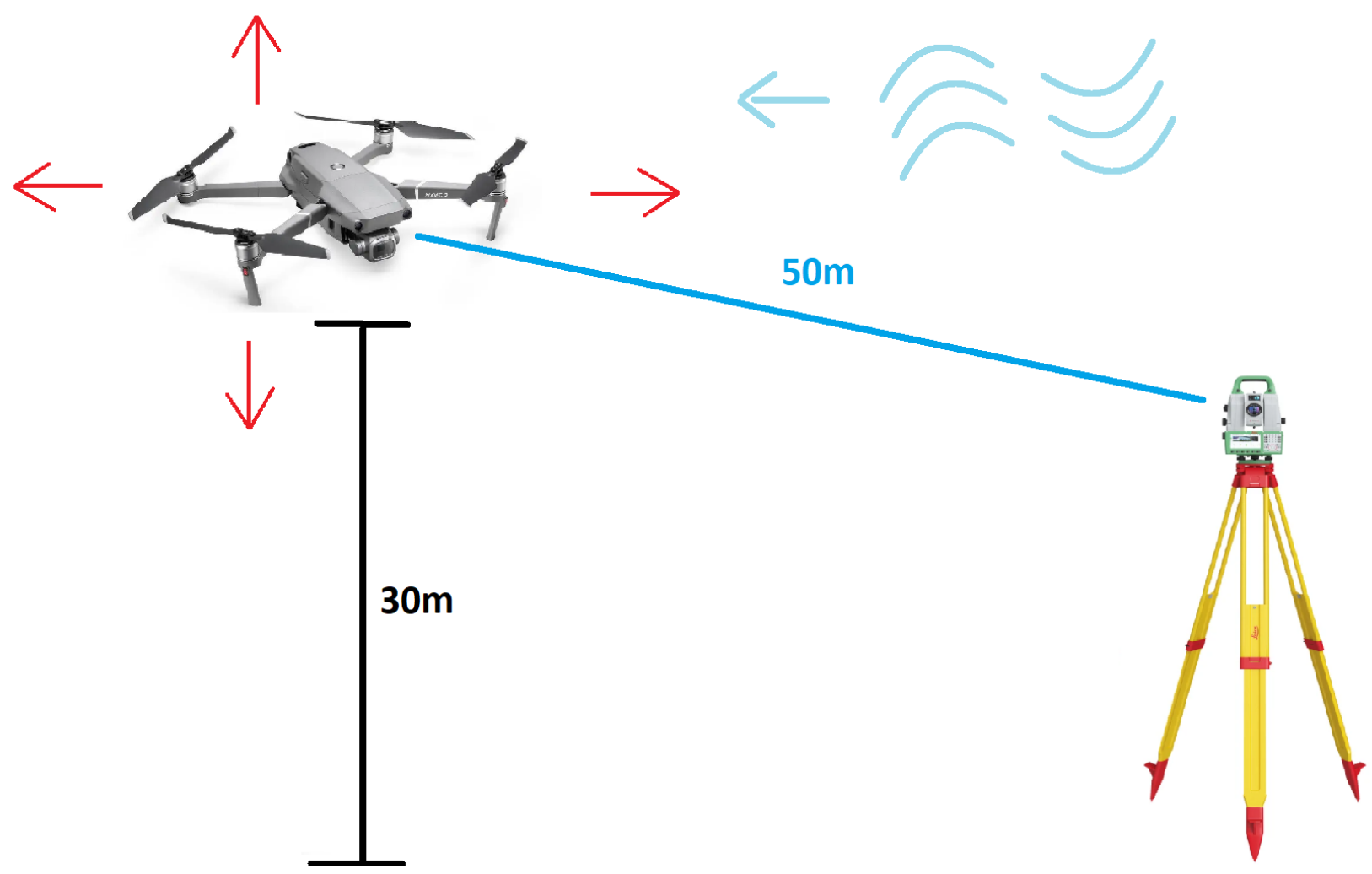

Fig. 3- Drone movement test scheme

\section{Theoretical precision analysis}

Free station task is calculated by measured angles and distances at known points. If the measurement contains redundant values that are subject to normal distribution, errors are adjusted by least squares.

The approximate coordinates must be known for the calculation, and it is calculated by different method like distance intersection [14] [15] [16].

In our example results of least squares are free station coordinates and orientation shift.

$$
X=\left(X_{c} Y_{c} Z_{c} o_{p}\right)^{T}
$$

Measured values on orientation points are horizontal direction, zenith angle, and distance.

$$
l=\left(\varphi_{1} \varphi_{2} \zeta_{1} \zeta_{2} s d_{1} s d_{2}\right)
$$

Each measured value is equation for unknown results.

$$
t=f(X)
$$

Equation of horizontal direction of orientation point:

$$
\varphi_{i j}=\arctan \left(\frac{Y_{j}-Y_{i}}{X_{j}-Y_{i}}\right)+o_{p}
$$

Equation of distance between orientation point and free station:

$$
s d_{i j}=\sqrt{\left(X_{j}-X_{i}\right)^{2}+\left(Y_{j}-Y_{i}\right)^{2}+\left(Z_{j}-Z_{i}\right)^{2}}
$$

Equation of zenith angle of orientation point: 


$$
\zeta_{i j}=\arccos \left(\frac{\left(Z_{j}-Z_{i}\right)}{\sqrt{\left(X_{j}-X_{i}\right)^{2}+\left(Y_{j}-Y_{i}\right)^{2}+\left(Z_{j}-Z_{i}\right)^{2}}}\right)
$$

Derivation matrix of equation of measured values:

$$
A=\left(\begin{array}{cccc}
\frac{\partial \varphi_{c j}}{\partial X_{c}} & \frac{\partial \varphi_{c j}}{\partial Y_{c}} & \frac{\partial \varphi_{c j}}{\partial Z_{c}} & \frac{\partial \varphi_{c j}}{\partial o_{p}} \\
\frac{\partial \varphi_{c i}}{\partial X_{c}} & \frac{\partial \varphi_{c i}}{\partial Y_{c}} & \frac{\partial \varphi_{c i}}{\partial Z_{c}} & \frac{\partial \varphi_{c i}}{\partial o_{p}} \\
\frac{\partial s d_{c j}}{\partial X_{c}} & \frac{\partial s d_{c j}}{\partial Y_{c}} & \frac{\partial s d_{c j}}{\partial Z_{c}} & \frac{\partial s d_{c j}}{\partial o_{p}} \\
\frac{\partial s d_{c i}}{\partial X_{c}} & \frac{\partial s d_{c i}}{\partial Y_{c}} & \frac{\partial s d_{c i}}{\partial Z_{c}} & \frac{\partial s d_{c i}}{\partial o_{p}} \\
\frac{\partial \zeta_{c j}}{\partial X_{c}} & \frac{\partial \zeta_{c j}}{\partial Y_{c}} & \frac{\partial \zeta_{c j}}{\partial Z_{c}} & \frac{\partial \zeta_{c j}}{\partial o_{p}} \\
\frac{\partial \zeta_{c i}}{\partial X_{c}} & \frac{\partial \zeta_{c i}}{\partial Y_{c}} & \frac{\partial \zeta_{c i}}{\partial Z_{c}} & \frac{\partial \zeta_{c i}}{\partial o_{p}}
\end{array}\right)
$$

Derivation matrix of equation of measured values after inserting derived derivatives:

$$
A=\left(\begin{array}{cccc}
\frac{\Delta Y_{c j}}{d_{c j}^{2}} & -\frac{\Delta X_{c j}}{d_{c j}^{2}} & 0 & 1 \\
\frac{\Delta Y_{c i}}{d_{c i}^{2}} & -\frac{\Delta X_{c i}}{d_{c i}^{2}} & 0 & 1 \\
-\frac{\Delta X_{c j}}{s d_{c j}} & -\frac{\Delta Y_{c j}}{s d_{c j}} & -\frac{\Delta Z_{c j}}{s d_{c j}} & 0 \\
-\frac{\Delta X_{c i}}{s d_{c i}} & -\frac{\Delta Y_{c i}}{s d_{c i}} & -\frac{\Delta Z_{c i}}{s d_{c i}} & 0 \\
-\frac{\Delta X_{c j} \cdot \Delta Z_{c j}}{d_{c j} \cdot s d_{c j}^{2}} & -\frac{\Delta Y_{c j} \cdot \Delta Z_{c j}}{d_{c j} \cdot s d_{c j}^{2}} & \frac{d_{c j}}{s d_{c j}^{2}} & 0 \\
-\frac{\Delta X_{c i} \cdot \Delta Z_{c i}}{d_{c i} \cdot s d_{c i}^{2}} & -\frac{\Delta Y_{c i} \Delta Z_{c i}}{d_{c i} \cdot s d_{c i}^{2}} & \frac{d_{c i}}{s d_{c i}^{2}} & 0
\end{array}\right)
$$

Scale matrix:

$$
P=\operatorname{diag}\left(p_{1} p_{2} p_{3} p_{4} p_{5} p_{6}\right)
$$

Individual's scale is given by a priori standard deviation and standard deviation of measured value:

$$
p_{i}=\frac{\sigma_{0}^{2}}{\sigma_{i}^{2}}
$$

Standard deviation of horizontal direction given by angle standard deviation, standard deviation of orientation point in horizontal plane and centration standard deviation:

$$
\sigma_{\varphi}=\sqrt{\sigma_{\bar{\varphi}}^{2}+\left(\frac{\sigma_{X Y}}{s d}\right)^{2}+\left(\frac{\sigma_{c}}{s d}\right)^{2}}
$$

Standard deviation of zenith angle given by angle standard deviation, standard deviation of orientation point in vertical axis and centration standard deviation:

$$
\sigma_{\zeta}=\sqrt{\sigma_{\bar{\zeta}}^{2}+\left(\frac{\sigma_{z}}{s d}\right)^{2}+\left(\frac{\sigma_{c}}{s d}\right)^{2}}
$$

Standard deviation of distance given by angle standard deviation, standard deviation of orientation point and centration standard deviation:

$$
\sigma_{s d}=\sqrt{\sigma_{\overline{s d}}^{2}+\sigma_{X Y Z}^{2}+\sigma_{c}^{2}}
$$


Covariance matrix:

$$
\Sigma=\sigma_{0}^{2} \cdot\left(A^{T} \cdot P \cdot A\right)^{-1}
$$

Standard deviation of free station in $\mathrm{X}$ axis:

$$
\sigma_{x}=\sqrt{\Sigma_{1,1}}
$$

Standard deviation of free station in $Y$ axis:

$$
\sigma_{y}=\sqrt{\Sigma_{2,2}}
$$

Standard deviation of free station in $\mathrm{Z}$ axis:

$$
\sigma_{z}=\sqrt{\Sigma_{3,3}}
$$

Standard deviation of orientation shift:

$$
\sigma_{O_{p}}=\sqrt{\Sigma_{4,4}} \cdot 200 / p i
$$

Standard deviation of free station in horizontal plane:

$$
\sigma_{x y}=\sqrt{\frac{\Sigma_{1,1}+\Sigma_{2,2}}{2}}
$$

Orientation of standard deviation is not identical to coordinates system. The largest value will take effect depending on configuration of orientation points. Error ellipse solves this problem.

Twist angle of error ellipse:

$$
\operatorname{tg}(2 \omega)=\frac{2 \sigma_{x y}}{\sigma_{x}^{2}-\sigma_{y}^{2}}
$$

Standard deviation main half axis of error ellipse:

$$
\sigma_{\xi}^{2}=\sigma_{x}^{2} \cdot \cos ^{2}(\omega)+\sigma_{x y} \cdot \sin (2 \omega)+\sigma_{y}^{2} \cdot \sin ^{2}(\omega)
$$

Standard deviation second half axis of error ellipse:

$$
\sigma_{\eta}^{2}=\sigma_{x}^{2} \cdot \sin ^{2}(\omega)-\sigma_{x y} \cdot \sin (2 \omega)+\sigma_{y}^{2} \cdot \cos ^{2}(\omega)
$$

\section{Precision analysis}

Free station task analysis was divided into two sections. Both analyses deal with position accuracy of free station. Inputs are two points with coordinates $(X, Y, Z)$ and free station in the centre of the coordinate system. The position of the two points changes depending on analysis. Standard deviation of orientation shift and main half axis of error ellipse are monitored in both analyses. Standard deviation of orientation shift is monitored because it directly affects the following measurement from a free station.

\section{Horizontal and vertical angles}

Inputs are two point coordinates $(X, Y, Z)$ and free station in the centre of the coordinate system. Two points lay on a sphere with a $50 \mathrm{~m}$ radius. Horizontal angle between orientation points is changing in span 0 to 200 gon. The zenith angle is changing for each orientation point the same in span $0-100$ gon. The standard deviation of orientation shift and main half axis of error ellipse are monitored depending on changing angles. The results can be found in Figures 4 and 5.

\section{Horizontal angle and distance}

Inputs are two point with coordinates $(X, Y, Z)$ and free station in centre of the coordinate system. Two points lie in plain. Horizontal angle between two points is changing interval from 0 to 
200 gon. At the same time distance between free station and points is changing in interval $1-50 \mathrm{~m}$. The standard deviation of orientation shift and main half axis of error ellipse are monitored depending on changing horizontal angle and distance. The results can be seen in the Figures 6 and 7 .

\section{RESULTS}

\section{Drone position experiment}

Vertical movements are smaller than horizontal movements. This is due to the wind direction, which affects the drone more in a horizontal direction.

Tab. 1 - Results 1 Drone movements

\begin{tabular}{|l|l|l|}
\hline & No Wind $(5 \mathrm{~m} / \mathrm{s})$ & Wind $(15 \mathrm{~m} / \mathrm{s})$ \\
\hline $\begin{array}{l}\text { Horizontal } \\
\text { position } \\
\text { accuracy }\end{array}$ & $0.049[\mathrm{~m}]$ & $0.098[\mathrm{~m}]$ \\
\hline $\begin{array}{l}\text { Vertical } \\
\text { position } \\
\text { accuracy }\end{array}$ & $0.018[\mathrm{~m}]$ & $0.036[\mathrm{~m}]$ \\
\hline $\begin{array}{l}\text { Max } \\
\text { difference }\end{array}$ & $0.081[\mathrm{~m}]$ & $0.143[\mathrm{~m}]$ \\
\hline
\end{tabular}

Tab. 2 - Results 2 Drone movements

\begin{tabular}{|l|l|l|}
\hline & No Wind $(5 \mathrm{~m} / \mathrm{s})$ & Wind $(15 \mathrm{~m} / \mathrm{s})$ \\
\hline $\begin{array}{l}\text { Horizontal } \\
\text { position } \\
\text { accuracy }\end{array}$ & $0.065[\mathrm{~m}]$ & $0.095[\mathrm{~m}]$ \\
\hline $\begin{array}{l}\text { Vertical } \\
\text { position } \\
\text { accuracy }\end{array}$ & $0.026[\mathrm{~m}]$ & $0.038[\mathrm{~m}]$ \\
\hline $\begin{array}{l}\text { Max } \\
\text { difference }\end{array}$ & $0.075[\mathrm{~m}]$ & $0.163[\mathrm{~m}]$ \\
\hline
\end{tabular}


CIVIL

ENGINEERING JOURNAL

\section{Free station task analysis}

Tab. 3 - Standard deviation of measurement values

\begin{tabular}{|c|l|l|}
\hline & $\begin{array}{l}\text { standard } \\
\text { deviation }\end{array}$ & Used value \\
\hline$\sigma_{\varphi}$ & $\begin{array}{l}\text { Horizontal } \\
\text { direction }\end{array}$ & $1 \mathrm{mgon}$ \\
\hline$\sigma_{\zeta}$ & $\begin{array}{l}\text { Vertical } \\
\text { direction }\end{array}$ & $1 \mathrm{mgon}$ \\
\hline$\sigma_{X Y}$ & $\begin{array}{l}\text { orientation } \\
\text { point }\end{array}$ & $5 \mathrm{~cm}$ \\
\hline$\sigma_{Z}$ & $\begin{array}{l}\text { orientation } \\
\text { point }\end{array}$ & $3 \mathrm{~cm}$ \\
\hline$\sigma_{c}$ & centration & $7 \mathrm{~mm}$ \\
\hline$\sigma_{s d}$ & distance & $2 \mathrm{~mm}+2 \mathrm{ppm}$ \\
\hline
\end{tabular}

Precision of orientation points increases with greater distance and with greater horizontal angle between orientation points as shown in the results. Ideology can be imagined in drawing the intersection of two lines. When two lines are perpendicular on each other, the intersection can be clearly seen. When the angle of intersection is too small, the intersection is not precisely defined and appears as a small line. It is the same as in a case of free station task, when the horizontal angle is too small precision is worse.

\section{Horizontal and vertical angles}

These results show length main half axis of error ellipse, standard deviation of orientation shift and standard deviation of vertical position acquire from changing horizontal and vertical angles. The results are showed on 3D graph and its contour on Figure 3 and 4. Multiple graphs on Figure 3 shows standard deviation of orientation shift and main half axis of error ellipse. Main half axis of error ellipse was selected, because it is the best indicator of horizontal precision of two values (coordinates $X$ and $Y$ ) and takes configuration of orientation points into consideration. Standard deviation of orientation shift is indicator of bad measurement of horizontal angles. The greater its value the greater the uncertainty in measuring horizontal angles. Graphs on Figure 4 shows standard deviation of vertical position. It indicates precision in vertical axis. 

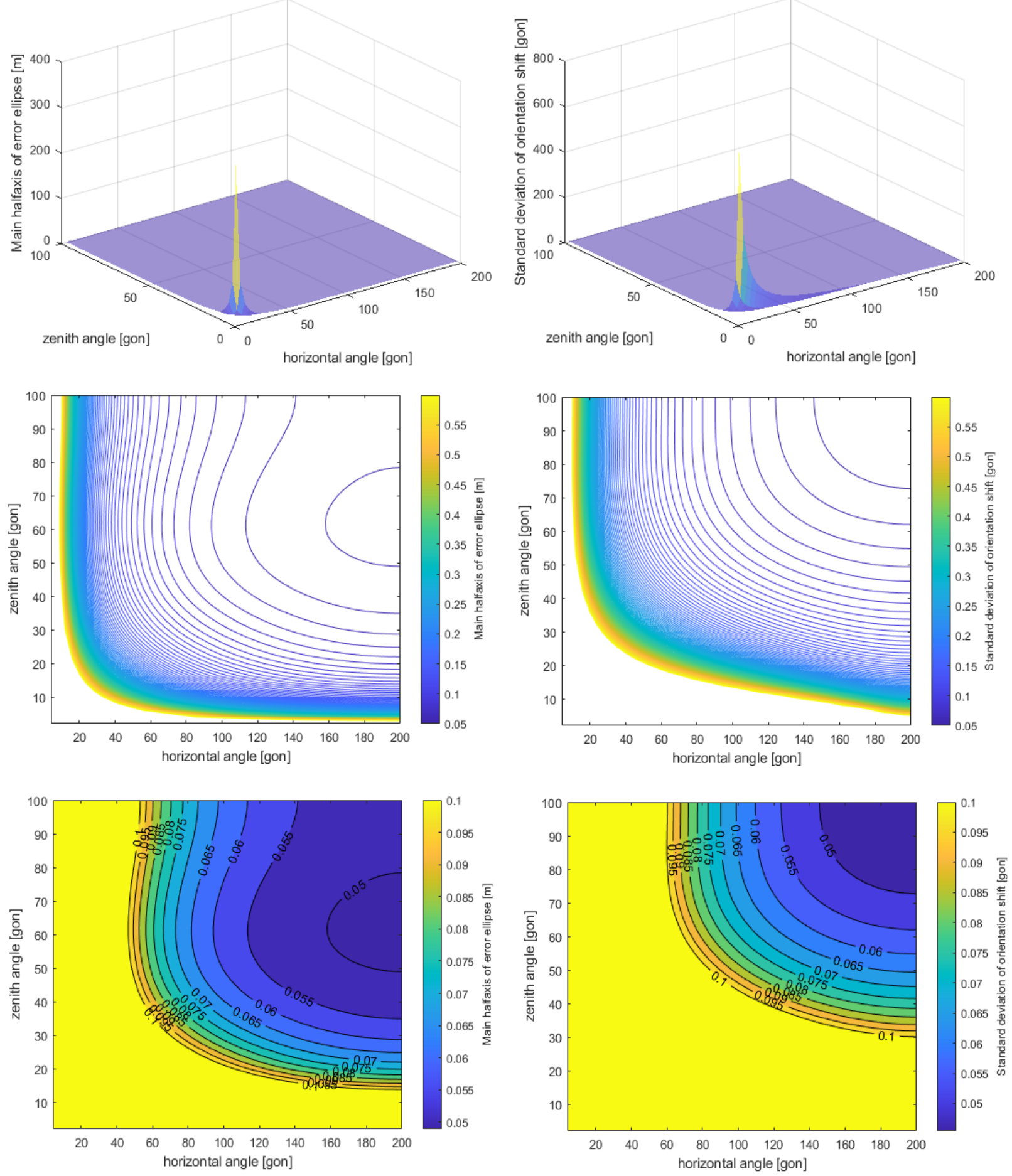

Fig. 4 - Precision analysis - main half axis of error ellipse (left column), orientation shift (right column) 


\section{JOURNAL}


Fig. 5 - Precision analysis - vertical position

\section{Horizontal angle and distance}

These results show length main half axis of error ellipse, standard deviation of orientation shift and standard deviation of vertical position acquire from changing horizontal angle and distance. The results are showed on 3D graph and its contour in Figures 5 and 6. Multiple graphs in Figure 5 shows standard deviation of orientation shift and main half axis of error ellipse. Graphs in Figure 6 shows standard deviation of vertical position. It indicates precision in vertical axis. 

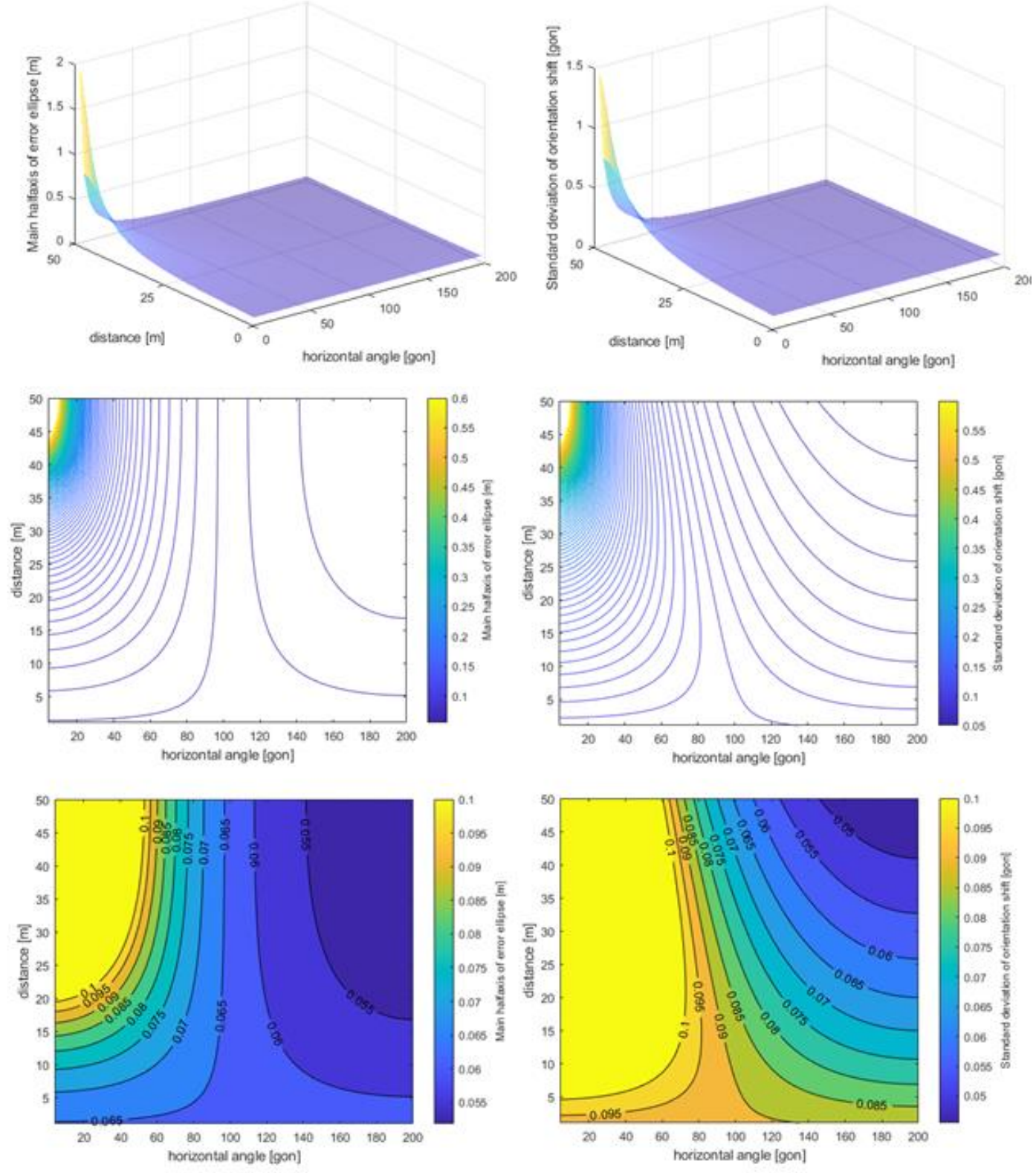

Fig. 6 - Precision analysis - main half axis of error ellipse (left column), orientation shift (right column) 


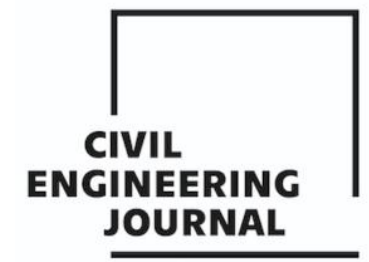

Article no. 57

THE CIVIL ENGINEERING JOURNAL 3-2021

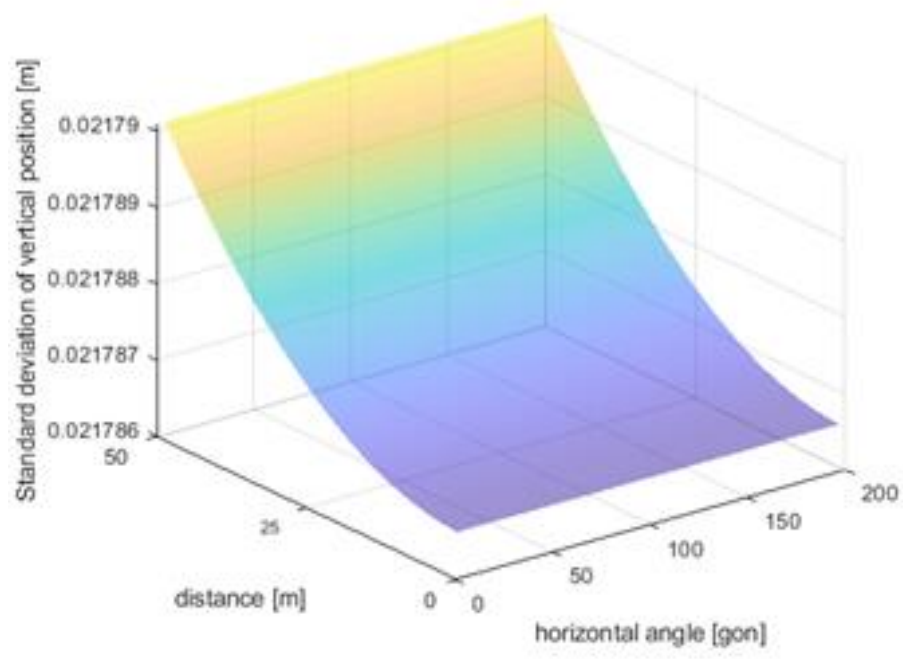

Fig. 7 - Precision analysis - vertical position

\section{CONCLUSION}

A drone equipped with GNSS RTK and prism can be used as orientation points. The conditions must be noticed, and high position accuracy of the free station must not be required. Position accuracy free station coordinates mainly depend on position accuracy of orientation points. Position accuracy of orientation points also depends on GNSS measurement and weather conditions. Drone can be used as an orientation point when it is not windy (e.g. up to $5 \mathrm{~m} / \mathrm{s}$ ). Standard deviation of orientation points was determined by drone movements test. Horizontal value is $5 \mathrm{~cm}$ and vertical is $3 \mathrm{~cm}$. The accuracy of the GNSS receiver is better $(1 \mathrm{~cm}+1 \mathrm{ppm})$ than the drone movements standard deviation from results. Drone movements standard deviation is used for precision analysis as standard deviation of orientation points.

Horizontal position precision of a free station is mainly dependent on precision of orientation points. Configuration of orientation points has some considerable effect especially in extreme cases. Results show that with longer distance between orientation points and total station, position and orientation shift accuracy is better. Horizontal distance has the greatest effect on the accuracy of the orientation shift. Horizontal angle between control points is recommended to keep above 80 gon as can be seen in the results. Zenith angle of orientation points has minimal effect on position precision of free station. Short horizontal distance between free station and orientation points has a bad effect on orientation shift accuracy. Horizontal distance must be longer than $30 \mathrm{~m}$.

Configuration of orientation points does not have much effect on vertical position precision. The result was expected. Vertical position is calculated independently from both orientation points by trigonometry. Vertical position precision mainly depends on position accuracy of orientation points.

Two surveyors are needed in this method. First surveyor uses a total station and the second surveyor flies with a drone. Drone movements are expected e.g. up $10 \mathrm{~cm}$. This value comes from the drone movements test, and it is the maximum horizontal change in position. Total station with automatic targeting handles drone movement. Angles change from slightly moving drone is $0.1 \mathrm{gon}$. In the future it would be appropriate to test the method directly in the field. Free station would be calculated from orientation points on the ground. In the next step free station would be calculated from orientation points done by drone. Differences will confirm theoretical precision analysis in this article. 


\section{$\prod_{\text {CIVIL }}$ JOURNAL}

\section{ACKNOWLEDGEMENTS}

This work was supported by the Grant Agency of the Czech Technical University in Prague, grant No. SGS21/054/OHK1/1T/11

\section{REFERENCES}

[1] Gupta, Sharad Kumar; Shukla, Dericks P. Application of drone for landslide mapping, dimension estimation and its 3D reconstruction. Journal of the Indian Society of Remote Sensing, 2018, 46.6: 903-914.

[2] Tiwari, Nidhi P., et al. Advanced techniques used in surveying: total station, GPS, GIS, DRONE Arial survey. International Journal for Research in Applied Science and Engineering Technology, 2018, 6.3: 896902.

[3] Jimenez-Cano, A.E.; Sanchez-Cuevas, P.J.; Grau, P.; Ollero, A.; Heredia, G. Contact-Based Bridge Inspection Multirotors: Design, Modeling, and Control Considering the Ceiling Effect. IEEE Robot. Autom. Lett. 2019, 4, 3561-3568. [Google Scholar] [CrossRef]

[4] Suzuki, Takayuki; Kumagai, Taichi; Yoshida, Hiroshi. Accuracy evaluation of drone control system using total station. IEICE Technical Report; IEICE Tech. Rep., 2020, 119.461: 67-72.

[5] Delgado, Javier Prada, et al. Bridge mapping for inspection using an UAV assisted by a total station. In: Iberian Robotics conference. Springer, Cham, 2017. p. 309-319.

[6] Maxim, Artyom, et al. UAV Guidance with Robotic Total Station for Architectural Fabrication Processes. Unmanned Aerial Vehicles; Wißner-Verlag: Augsburg, Germany, 2017, 145-161.

[7] ISHII, A., et al. Autonomous UAV flight using the Total Station Navigation System in Non-GNSS Environments. In: ISARC. Proceedings of the International Symposium on Automation and Robotics in Construction. IAARC Publications, 2020. p. 685-692.

[8] Hankus-Kubica, Agnieszka, et al. Verification tests of total station usability for UAV position measurements. In: 2020 IEEE 7th International Workshop on Metrology for AeroSpace (MetroAeroSpace). IEEE, 2020. p. 331-335.

[9] CivDot, https://www.civrobotics.com/

[10] Jan, Šikola. Testování GNSS modulu Ublox 9. generace. 2020. Master's Thesis. České vysoké učení technické v Praze. Vypočetní a informační centrum.

[11] Wielgocka, N.; Hadas, T.; Kaczmarek, A.; Marut, G. Feasibility of Using Low-Cost Dual-Frequency GNSS Receivers for Land Surveying. Sensors 2021, 21, 1956. https://doi.org/10.3390/s21061956

[12] Hamza, V.; Stopar, B.; Sterle, O. Testing the Performance of Multi-Frequency Low-Cost GNSS Receivers and Antennas. Sensors 2021, 21, 2029. https://doi.org/10.3390/s21062029

[13] Zahradník, D. Hodík, Š. Vyskočil, Z. Ublox F9P for geodetic measurment Stavební obzor-Civil Engineering Journal 30.3 (2021).

[14] Štroner, M. - Hampacher, M.: Process and analyses surveying measurment (Zpracování a analýza měření v inženýrské geodézii). 1. vyd. Praha: CTU Publishing House, 2011. 313 s. ISBN 978-80-01-04900-6.

[15] Štroner, M.: Free station task precision ( $K$ přesnosti volného stanoviska). Geodetický a kartografický obzor. 2012, roč. 58, č. 8, s. 170-176. ISSN 0016-7096

[16] Andrew Marshall, Analysis of free station errors, Surv431 Engineering Surveying at the National School of Surveying in 2007 